\title{
Collagen VI Encodes Antimicrobial Activity: Novel Innate Host Defense Properties of the Extracellular Matrix
}

\author{
Suado M. Abdillahi Selma Balvanović Maria Baumgarten Matthias Mörgelin \\ Division of Infection Medicine, Department of Clinical Sciences, Biomedical Center, Lund University, Lund, Sweden
}

\author{
Key Words \\ Antimicrobial activity • Innate host defense • \\ Collagen type VI • Extracellular matrix · Streptococcus • \\ Oral pathogens
}

\begin{abstract}
Collagen type VI is a subepithelial extracellular matrix component in airways and an adhesive substrate for oral pathogens [Bober et al.: J Innate Immun 2010;2:160-166]. Here, we report that collagen $\mathrm{VI}$ displays a dose-dependent antimicrobial activity against group A, C, and G streptococci by membrane disruption in physiological conditions. The data disclose previously unrecognized aspects of the extracellular matrix in innate host defense.
\end{abstract}

Copyright $\odot 2012$ S. Karger AG, Basel

\section{Introduction}

Collagen type VI is a ubiquitous fibrillar component of the mammalian extracellular matrix [for references, see 1-3]. It is present in most connective tissues, often associated with basement membranes. The collagen VI subunits are heterotrimers composed of $\alpha 1, \alpha 2$, and $\alpha 3$ polypeptide chains, where additional tissue-specific chains $(\alpha 4, \alpha 5$, and $\alpha 6)$ may substitute for the $\alpha 3$ chain in some situations $[2,4]$. Structurally the $\alpha$-chains are organized as dumb-bell-shaped monomers, where a short extended triple-helical region is flanked by two large $\mathrm{N}$ - and $\mathrm{C}$-terminal globular regions. Four monomers align to tetramers by lateral association, which then aggregate endon-end to microfibrils that become part of extended supramolecular matrix assemblies. The $\mathrm{N}$ - and C-terminal globular domains share homology with von Willebrand factor type A domains [5]. Interestingly, von Willebrand factor harbors cationic sequence motifs associated with heparin affinity that may confer antimicrobial properties [6]. Similar motifs are contained in the collagen VI sequence [5] and are conserved between different species.

Group A streptococcus is an exclusive human pathogen that preferentially colonizes pharyngeal epithelium, skin, and soft tissues. Infections may cause pneumonia and serious invasive conditions like septicemia, toxic shock syndrome, and necrotizing fasciitis [recently reviewed in 7]. Group C and G streptococci are commonly isolated as commensals from upper airways, skin, and the gastrointestinal tract, but they are also associated with infections of serious clinical importance. They may cause a spectrum of diseases similar to those caused by group A streptococci, from pharyngitis and impetigo to severe conditions such as necrotizing fasciitis [for references, see 8]. Pharyngeal carriage of these bacteria may be an underlying cause of acute rheumatic fever [9].

\section{KARGER}

Fax +4161306 1234

E-Mail karger@karger.ch

www.karger.com
(C) 2012 S. Karger AG, Basel

1662-811X/12/0044-0371\$38.00/0

Accessible online at:

www.karger.com/jin
Dr. Matthias Mörgelin

Department of Clinical Sciences, Biomedical Center

Floor B14, Lund University

SE-221 84 Lund (Sweden)

Tel. +46 46222 0741, E-Mail matthias.morgelin@med.lu.se 
Primary adhesion to host targets is generally considered to be crucial in bacterial pathogenesis [10], enabling the microbe to successfully invade and colonize the host and bypass host defense mechanisms [11]. In addition to cell surface receptors, extracellular matrix components such as collagen I and IV, fibronectin, laminin, and vitronectin have been reported to be microbial target structures [for references, see 11-13]. Recently, we identified collagen VI as an adhesive substrate for oral pathogens Streptococcus pyogenes and Streptococcus pneumoniae. M1 protein was identified as a collagen VI binding adhesin of $S$. pyogenes [1].

During these studies, given the fact that the collagen VI sequence contains cationic motifs with antimicrobial potential, we were prompted to ask whether this intriguing multidomain molecule exerts antibacterial activity. Indeed, our data disclose a previously unrecognized antimicrobial potential of collagen type VI against oral pathogens. Killing of A, C, and G streptococci occurs in a dose-dependent way by membrane permeabilization in physiological conditions. As a consequence, extracellular matrix components may protect from pathogen invaders by aiding innate host defense responses that are beneficial in early stages of infection.

\section{Materials and Methods}

Microorganisms and Culture Conditions

The following bacterial strains were kindly provided by IngaMaria Frick (Department of Infection Medicine, Lund University): group A streptococcus AP1 (strain 40/58 of the M1 serotype) and isogenic mutants lacking protein M1 (BMJ11), protein $\mathrm{H}$ (BMJ27.6), or both M1 and H (BMJ71) [14]; group C streptococcus C16 and C36 [15, 17], and group G streptococcus G41 and G148 $[16,17]$. All strains were grown overnight in Todd-Hewitt broth (THB; Gibco, Grand Island, N.Y., USA) at $37^{\circ} \mathrm{C}$ in a humid atmosphere containing $5 \% \mathrm{CO}_{2}$. BMJ11 and BMJ71 were supplemented with tetracycline $(5 \mu \mathrm{g} / \mathrm{ml})$, and for BMJ27.6, erythromycin $(1 \mu \mathrm{g} /$ $\mathrm{ml}$ ) was added to the THB medium.

\section{Isolation of Type VI Collagen}

Collagen type VI microfibrils were extracted from bovine cornea by collagenase digestion as described by Spissinger and Engel [18] with some modifications. Calf eyes were obtained from the local abattoir. Corneas were dissected and cut into pieces in digestion buffer: $50 \mathrm{mM}$ Tris- $\mathrm{HCl}, 150 \mathrm{mM} \mathrm{NaCl}$, and $5 \mathrm{mM} \mathrm{CaCl}_{2}(\mathrm{pH}$ 7.4), supplemented with proteinase inhibitors: $10 \mathrm{mM} \mathrm{N}$-ethylmaleimide, $2 \mathrm{mM}$ phenylmethanesulfonylfluoride, $10 \mathrm{~mm}$ benzamidine hydrochloride, and $100 \mathrm{~mm}$ aminocaproic acid. The corneas were homogenized in digestion buffer using a Polytron homogenizer (Kinematica AG, Littau, Switzerland), followed by digestion with $20 \mathrm{mg}$ bacterial collagenase IA (197 U/mg; Worthington, N.J., USA) per gram of wet tissue in digestion buffer overnight at room temperature under gentle stirring. The digest was centrifuged at $32,000 \mathrm{~g}$ for $30 \mathrm{~min}$ at $4^{\circ} \mathrm{C}$ and the supernatant was applied to a Sepharose CL-2B column (Pharmacia, Uppsala, Sweden) in TBS ( $50 \mathrm{~mm}$ Tris- $\mathrm{HCl}, 150 \mathrm{mM} \mathrm{NaCl}, \mathrm{pH}$ 7.4). The column (column volume 2 liters) was run at $2 \mathrm{ml} / \mathrm{min}$ and $10-\mathrm{ml}$ fractions were collected. The protein content was determined at $280 \mathrm{~nm}$ in a spectrophotometer and protein-containing void volume fractions were examined by electron microscopy. The purity was confirmed by mass spectral analysis (MALDI-TOF Voyager; Applied Biosystems, Foster City, Calif., USA). The collagen type VI-containing samples were stored at $4^{\circ} \mathrm{C}$ until further use.

\section{Antibacterial Activity Assay}

Bacteria were grown to the mid logarithmic phase in ToddHewitt broth $\left(\mathrm{OD}_{620} \approx 0.4\right)$, harvested by centrifugation at 3,500 rpm for $10 \mathrm{~min}$, and washed twice in TBS buffer. Bacterial suspensions were adjusted to $2 \times 10^{9}$ colony-forming units ( $\mathrm{cfu}$ ) per $\mathrm{ml}$. The bacteria were further diluted in TBS and incubated with different collagen VI concentrations $(10 \mathrm{nM}, 100 \mathrm{nM}$, or $2 \mu \mathrm{M}$, respectively). Bacteria incubated with TBS or $3 \mu \mathrm{M}$ LL-37 (Innovagen, Lund, Sweden) were used as controls. Samples were incubated for $2 \mathrm{~h}$ at $37^{\circ} \mathrm{C}$ in a humid atmosphere containing $5 \% \mathrm{CO}_{2}$. Serial dilutions were plated on blood agar plates and incubated overnight at $37^{\circ} \mathrm{C}, 5 \% \mathrm{CO}_{2}$, and the number of cfu was thereafter determined by counting visible colonies. Experiments were performed in triplicate.

\section{Transmission Electron Microscopy}

For negative staining and transmission electron microscopy, samples were adsorbed onto 400 mesh carbon-coated copper grids and stained with $0.75 \%(\mathrm{w} / \mathrm{v})$ uranyl formate as recently described in detail [19]. Samples were observed in an FEI Tecnai ${ }^{\mathrm{TM}}$ G2 Spirit (North America NanoPort, Hillsboro, Oreg., USA) transmission electron microscope operated at $60 \mathrm{kV}$ accelerating voltage. Images were recorded with an Olympus SIS Veleta CCD camera.

\section{Results}

\section{Collagen Type VI Is Antimicrobial against}

\section{S. pyogenes}

In order to assess possible antibacterial effects of collagen type VI, we treated S. pyogenes with purified preparations of this protein. Bacteria treated with TBS buffer or the cathelicidin peptide LL-37 [20] served as negative and positive controls, respectively. The results from viable-count assays show dose-dependent killing of AP1 (fig. 1a). Treatment with collagen VI for $2 \mathrm{~h}$ at $37^{\circ} \mathrm{C}$ significantly inhibited the growth of $S$. pyogenes as compared to control bacteria treated with TBS. Different collagen VI concentrations between $10 \mathrm{nM}$ and $2 \mu \mathrm{M}$ were applied. Notably, at micromolar collagen concentrations the efficiency of bacterial clearance was comparable to the 'classical' human antimicrobial peptide LL-37. 
Collagen VI Killing Properties Are Associated with Streptococcal Membrane Disruption

For a more detailed understanding of the underlying killing mechanism, streptococci were incubated with $1 \mu \mathrm{M}$ collagen VI and visualized by negative staining and electron microscopy. Figure $1 \mathrm{~b}-\mathrm{e}$ depicts the sequence of events leading to bacterial inactivation. Initially, collagen VI microfibrils adhere to the streptococcal surface (fig. 1b) as reported previously [1]. The globular von Willebrand A domains of the collagen are frequently seen in close contact with surface structures (fig. lb, c, asterisks). Subsequent to this initial step, membrane perturbations, blebbing (fig. 1c, arrowheads), and exudation of cytoplasmic content (fig. 1c, arrows) are observed. Large scale membrane destabilization events (fig. 1d, arrowhead) finally lead to disintegration of the bacterial cells into a mixture of membrane vesicles and cytoplasmic ejecta (fig. 1e). Taken together, the data presented in figure 1 show that collagen type VI exerts antimicrobial activity against AP1 by membrane rupture. The effect is dose dependent at physiological $\mathrm{pH}$ and salt concentrations.

\section{Killing of Group A Streptococci Correlates to M1 \\ Surface Protein Expression}

Adherence to the bacterial surface and interaction with the membrane are a prerequisite for the antimicrobial action of a given antimicrobial agent. We have recently shown that on the S. pyogenes surface protein M1 is an adhesin for collagen VI. Another important virulence factor of $S$. pyogenes, protein $\mathrm{H}$, does not exhibit affinity for this collagen [1]. In order to delineate the antimicrobial properties of collagen VI in further detail, we analyzed isogenic mutant strains of $S$. pyogenes expressing or lacking these surface proteins and thus the ability to bind collagen VI. Wild-type AP1 bacteria and BMJ11 (M1 deficient), BMJ27.6 (protein H deficient), and BMJ71 (M1 and $\mathrm{H}$ deficient) [14] were used in antimicrobial assays as described above. Indeed, streptococci lacking M1 protein, i.e. BMJ11 and BMJ71, showed a considerably higher viability than AP1 or the protein $\mathrm{H}$ mutant BMJ27.6 (fig. 2a). These results were confirmed by negative staining and transmission electron microscopy (fig. 2b). The M1 protein-expressing strains AP1 and BMJ 27.6 were more affected by membrane rupture and cytoplasmic exudation than the M1 mutants. Although BMJ 11 and BMJ 71 were somewhat affected as compared to control bacteria, they were less prone to killing by collagen VI. These findings suggest a crucial role for the interaction between collagen VI and M1 protein during the elimination of A streptococcus.

Antimicrobial Activity of Collagen VI
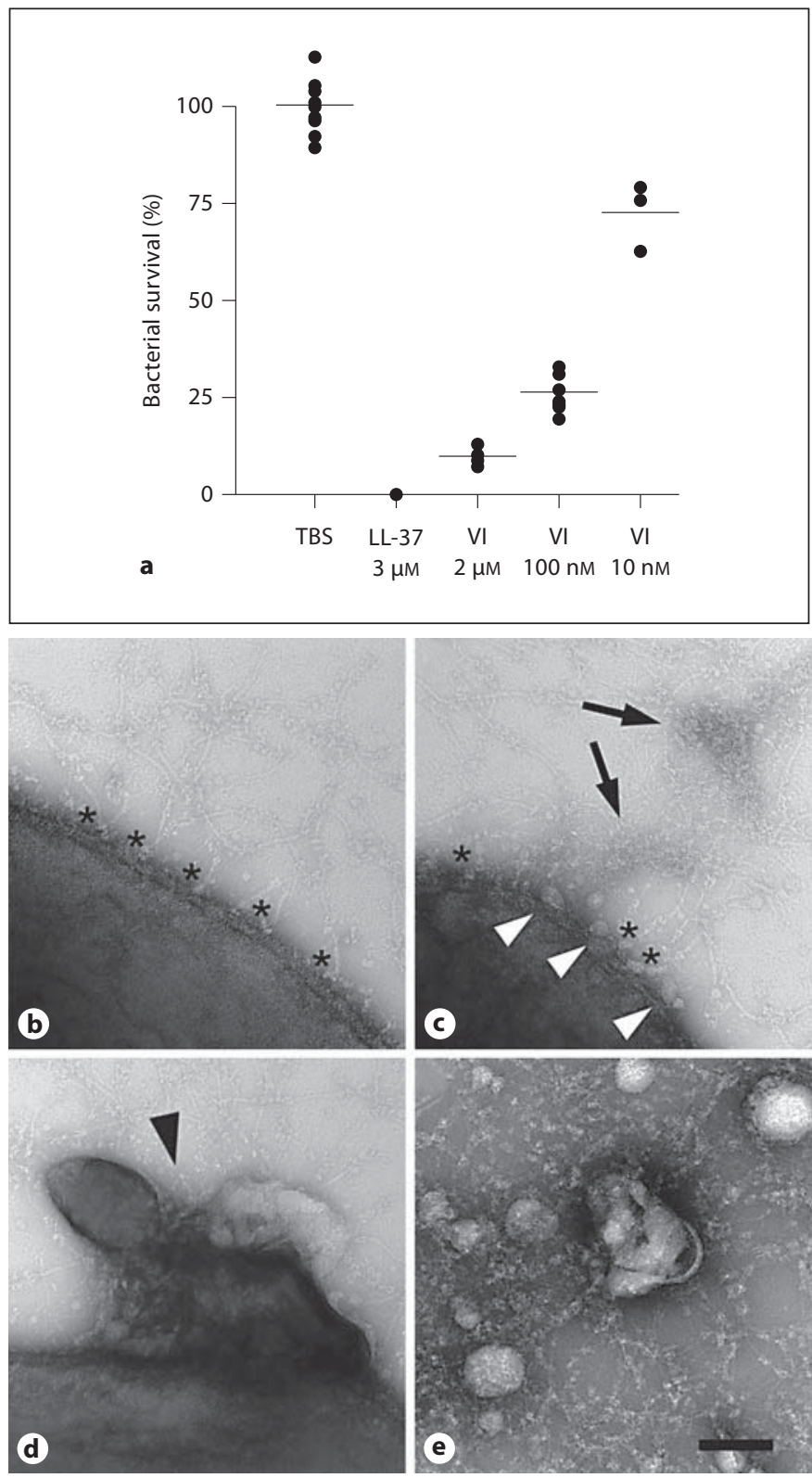

Fig. 1. Collagen type VI microfibrils induce killing of group A streptococcus by membrane destabilization. Antibacterial activity assay with $S$. pyogenes and collagen VI. AP1 bacteria were incubated with different concentrations of collagen VI for $2 \mathrm{~h}$ at $37^{\circ} \mathrm{C}$. Bacteria incubated with TBS buffer or with LL-37 served as negative or positive controls, respectively (a). Molar concentrations are indicated in the figure. The dots represent individual experiments with the respective strain. $\mathbf{b}-\mathbf{d}$ Negative staining and transmission electron microscopy of streptococcal membrane destabilization upon incubation with collagen VI. Initially, collagen microfibrils assemble at the bacterial surface (b). The globular von Willebrand A domains of collagen VI are often observed close to the bacterial surface (asterisks). Subsequently, membrane blebbing (c, arrowheads) and exudation of cytoplasmic content are visible (c, arrows). Large scale membrane disruption (d) finally leads to destruction of the bacteria cells (e). Scale bar $=100 \mathrm{~nm}$.

J Innate Immun 2012;4:371-376 

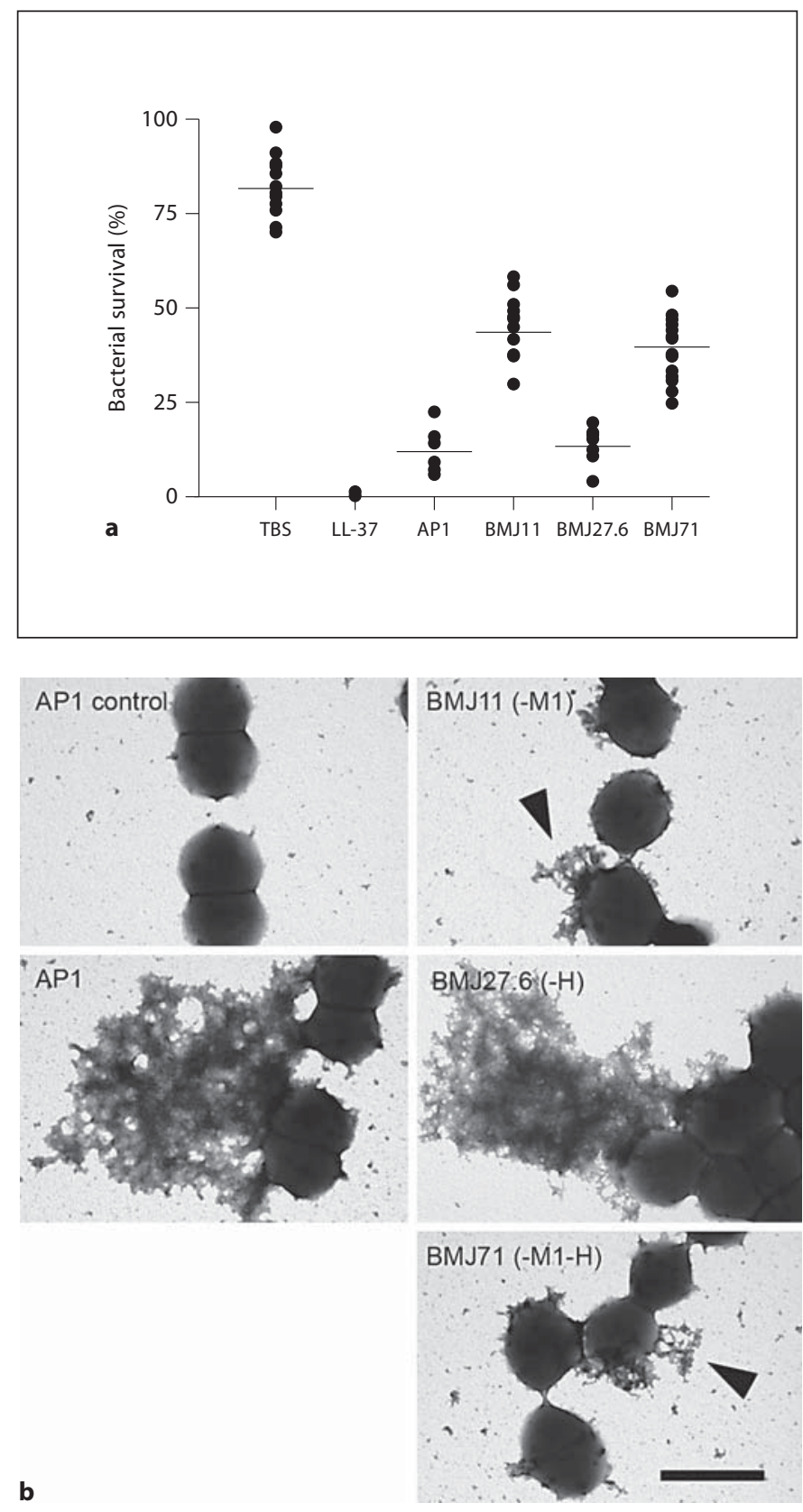

Fig. 2. Correlation between bacterial killing efficiency and expression of M1 surface protein. a Incubation of S. pyogenes wildtype strain AP1 and isogenic mutants BMJ11, BMJ27.6, and BMJ71 with $1 \mu \mathrm{M}$ collagen VI, followed by quantification of survival (cfu) in an antibacterial activity assay. In control samples bacteria were incubated with TBS buffer or LL-37. The dots represent individual experiments with the respective strain. b Specimens were analyzed by negative staining and electron microscopy. Scale bar = $1 \mu \mathrm{m}$. Mutants lacking M1 protein (BMJ11 and BMJ71) are less prone to growth inhibition (a) and membrane destabilization (b, arrowheads) than wild-type AP1 and the protein $\mathrm{H}$ mutant BMJ27.6.
Collagen VI Is Antimicrobial against Group A, C, and G Streptococci

To examine the antimicrobial properties of collagen VI towards a spectrum of oral pathogens, we tested patient isolates of group C and G streptococci in comparison to $S$. pyogenes. In viable count assays the bacterial growth of C16, C36, G41, and G148 was inhibited significantly, as observed for AP1. The collagen VI killing mechanism by membrane permeabilization was assessed by electron microscopic analysis. In contrast to incubation with TBS alone, all bacteria which were exposed to collagen VI exhibited membrane disruption and leakage of cytoplasmic material (fig. 3). For all examined streptococcal species this effect correlated with the collagen concentration, where micromolar concentrations of collagen VI (fig. 3c) exhibited a higher degree of membrane disruption than nanomolar doses (fig. 3b).

\section{Discussion}

This study demonstrates that collagen VI, a ubiquitous fibrillar extracellular matrix component, harbors antimicrobial activity against Gram-positive oral pathogens. Killing of group A, C, and G streptococci is dose dependent and occurs by membrane disruption in physiological conditions. Similar observations with Gram-negative microorganisms from the lower airways are under present investigation [Abdillahi, unpubl. res.]. The data uncover a previously unrecognized role of collagen VI as an innate host defense effector molecule in connective tissues.

The integrity of the airway mucosa is crucial for its protective properties against potentially invasive oral pathogens and diseases transmitted through the respiratory tract. When the epithelial cell layer is damaged by postviral infection injury or epithelial shedding, the underlying submucosa becomes exposed and vulnerable to pathogen invaders. In this scenario a repertoire of antimicrobial activity is beneficial to reduce the susceptibility of the tissue for infection. Indeed, during the past years evidence has emerged that connective tissues possess antimicrobial peptides related to extracellular matrix molecules as part of the natural tissue immune response $[6,21-23]$. Our data indicate that subepithelial collagen VI scaffolds, encoding both adhesive and antimicrobial properties, provide environments that may enhance innate antimicrobial protection in the respiratory tract. 
Fig. 3. Dose-dependent killing of group A, $\mathrm{C}$, and $\mathrm{G}$ streptococci by collagen VI. Electron microscopy of different streptococcus species after incubation with TBS (upper panel), $10 \mathrm{nM}$ collagen VI (middle panel), or $2 \mu \mathrm{M}$ collagen VI (lower panel). Group A streptococci (GAS), group C streptococci (GCS), and group G streptococci (GGS) are indicated in the figure. All different streptococci are killed by collagen VI in a dose-dependent manner by membrane permeabilization and cytoplasmic exudation. Scale bar $=1 \mu \mathrm{m}$.

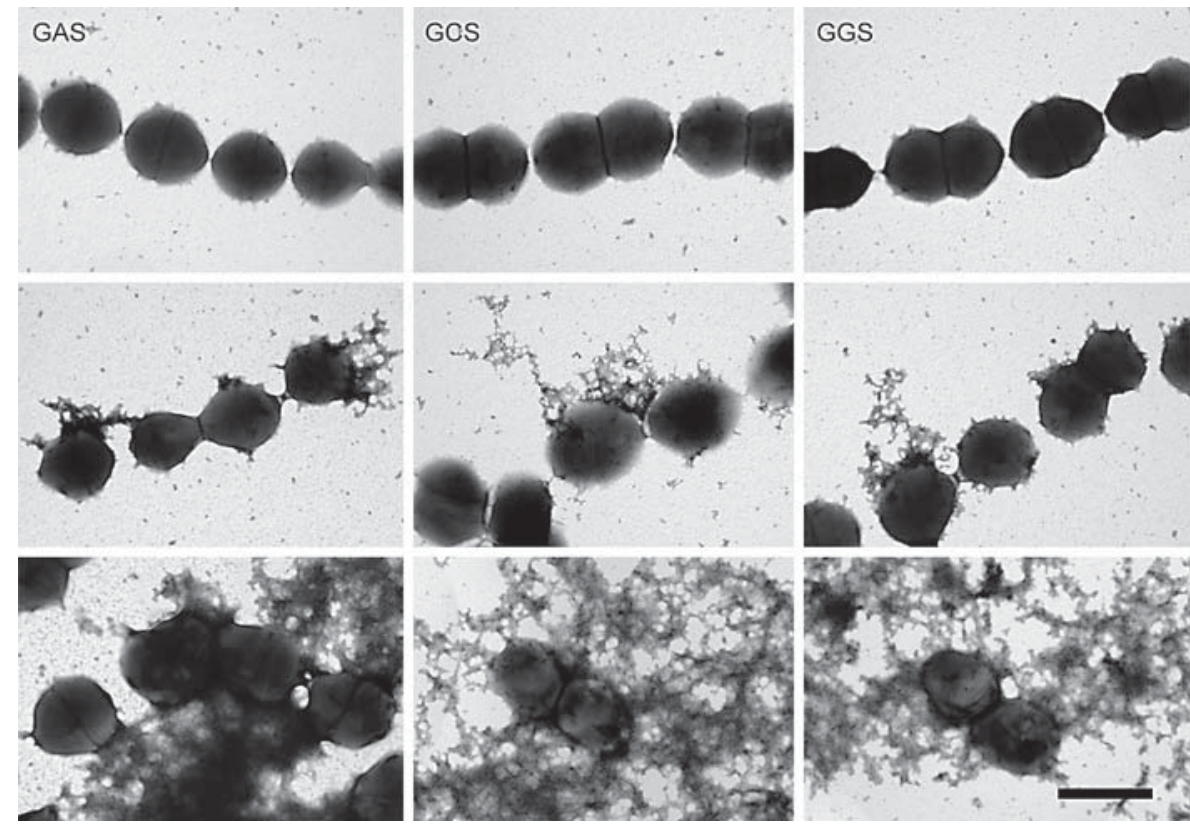

The killing efficiency of group A streptococcus was modulated by $\mathrm{M} 1$ protein, a recently identified collagen VI adhesin. In the absence of M1 on the streptococcal surface, killing was considerably less pronounced, indicating that the binding of collagen VI close to the bacterial membrane is crucial for its membrane-disrupting ability. The antibacterial effect was not completely abolished, though, suggesting that other still unrecognized collagen-binding surface structures might exist and promote some killing. These observations point to an inherent complex role of $\mathrm{M} 1$ protein in host-parasite interplay during infection. On the one hand, as a collagen VI adhesin, M1 is a streptococcal virulence factor facilitating host engagement and successful colonization. On the other hand, M1 can contribute to a microenvironment discouraging bacterial growth by targeting antimicrobial sites in the collagen VI molecule. This spectrum of innate adhesive and protective properties may cause different net effects in different scenarios of infection, highlighting the delicate balance in the host-microorganism relationship.

Electron microscopy showed that collagen VI induces a membrane permeabilization effect similar to the 'classical' antimicrobial cathelicidin peptide LL-37 [24-26]. Our data do not, however, demonstrate the exact killing mechanism by collagen VI because secondary metabolic effects may trigger bacterial death and membrane disruption. Even so, it is an intriguing hypothesis that col- lagen VI may directly target the bacterial membrane with its von Willebrand A domains. Subsequently, antimicrobial peptides in the A domains could inactivate the microbe by membrane destabilization, either directly within the A domains or released by bacterial or inflammatory proteases. In future work it will be important to identify and characterize such antimicrobial motifs in the collagen VI molecule.

\section{Acknowledgements}

We wish to thank Julie Chamoulaud, ITECH, Lyon, France, for assistance with bacterial killing assays. We gratefully acknowledge the help of Lina Gefors, Lund Bioimaging Center (LBIC), for help with electron microscopy. This work was supported by grants from the Swedish Research Council (project 7480), the Foundations of Crafoord, Johan and Greta Kock, Alfred Österlund, King Gustav V Memorial Fund, and the Medical Faculty at Lund University. 


\section{References}

1 Bober M, Enochsson C, Collin M, Mörgelin $\mathrm{M}$ : Collagen VI is a subepithelial adhesive target for human respiratory tract pathogens. J Innate Immun 2010;2:160-166.

-2 Gara SK, Grumati P, Squarzoni S, Sabatelli P, Urciuolo A, Bonaldo P, Paulsson M, Wagener R: Differential and restricted expression of novel collagen VI chains in mouse. Matrix Biol 2011;30:248-257.

$>3$ Tooley LD, Zamurs LK, Beecher N, Baker NL, Peat RA, Adams NE, Bateman JF, North KN, Baldock C, Lamandé SR: Collagen VI microfibril formation is abolished by an \{alpha\}2(VI) von Willebrand factor type A domain mutation in a patient with Ullrich congenital muscular dystrophy. J Biol Chem 2010;285:33567-33576.

4 Fitzgerald J, Rich C, Zhou FH, Hansen U: Three novel collagen VI chains, alpha4(VI), alpha5(VI), and alpha6(VI). J Biol Chem 2008;283:20170-20180.

$\checkmark 5$ Specks U, Mayer U, Nischt R, Spissinger T, Mann K, Timpl R, Engel J, Chu ML: Structure of recombinant $\mathrm{N}$-terminal globule of type VI collagen alpha 3 chain and its binding to heparin and hyaluronan. EMBO J 1992;11:4281-4290.

6 Andersson E, Rydengård V, Sonesson A, Mörgelin M, Björck, L, Schmidtchen A: Antimicrobial activities of heparin-binding peptides. Eur J Biochem 2004;271:12191226.

$>7$ Oehmcke S, Shannon O, Mörgelin M, Herwald $\mathrm{H}$ : Streptococcal $\mathrm{M}$ proteins and their role as virulence determinants. Clin Chim Acta 2010;411:1172-1180.

8 Oster HR, Bisno AL: Group C and Group G streptococcal infections: epidemiologic and clinical aspects; in Fischetti VA, Novik RP, Ferretti JJ, Portnoy DA, Rood JI (eds): The Gram-Positive Pathogens. Washington, American Society for Microbiology, 2000,pp 184-190.
$>9$ Haidan A, Talay SR, Rohde M, Sriprakash KS, Currie BJ, Chhatwal GS: Pharyngeal carriage of group $\mathrm{C}$ and group $\mathrm{G}$ streptococci and acute rheumatic fever in an Aboriginal population. Lancet 2000;356:1167-1169.

10 Dinkla K, Rohde M, Jansen WT, Carapetis JR, Chhatwal GS, Talay SR: Streptococcus pyogenes recruits collagen via surface-bound fibronectin: a novel colonization and immune evasion mechanism. Mol Microbiol 2003;47:861-869.

11 Patti JM, Allen BL, McGavin MJ, Höök M: MSCRAMM-mediated adherence of microorganisms to host tissues. Annu Rev Microbiol 1994;48:585-617.

12 Nitsche DP, Johansson HM, Frick IM, Mörgelin M: Streptococcal protein FOG, a novel matrix adhesin interacting with collagen I in vivo. J Biol Chem 2006;281:16701679 .

13 Hallström T, Singh B, Resman F, M Blom A, Mörgelin M, Riesbeck K: Haemophilus influenzae protein E binds to the extracellular matrix by concurrently interacting with laminin and vitronectin. J Infect Dis 2011; 204:1065-1074.

$\checkmark 14$ Kihlberg BM, Collin M, Olsén A, Björck L: Protein $\mathrm{H}$, an antiphagocytic surface protein in Streptococcus pyogenes. Infect Immun 1999;67:1708-1714.

15 Mjörner H, Albertsson PÅ, Kronwall G: Isoelectric points and surface hydrophobicity of gram-positive cocci as determined by crosspartition and hydrophobic affinity partition in aqueous two-phase systems. Infect Immun 1982;36:227-234.

16 Kronwall G, Myhre EB, Björck L, Berggård I: Binding of aggregated human $\beta 2$-microglobulin to surface protein structure in group $A, C$ and $G$ streptococci. Infect Immun 1978;22:136-142.

17 Widebäck K, Seal US, Kronwall G: Receptor in group $\mathrm{C}$ and $\mathrm{G}$ streptococci detects albumin structures present in mammalian species. Infect Immun 1982;36:469-475.
18 Spissinger T, Engel J: Type VI collagen beaded microfibrils from bovine cornea depolymerize at acidic $\mathrm{pH}$, and depolymerization and polymerization are not influenced by hyaluronan. Matrix Biol 1995;14:499-505.

19 Oehmcke S, Mörgelin M, Herwald H: Activation of the human contact system on neutrophil extracellular traps. J Innate Immun 2009; 1:225-230.

20 Sörensen OE, Follin P, Johnsen AH, Calafat J, Tjabranga GS, Hiemstra PS, Borregaard N: Human cathelicidin, hCAP-18, is processed to the antimicrobial peptide LL-37 by extracellular cleavage with proteinase 3 . Blood 2001;97:3951-3959.

21 Brennan EP, Reing J, Chew D, Myers-Irvin JM, Young EJ, Badylak SF: Antibacterial activity within degradation products of biological scaffolds composed of extracellular matrix. Tissue Eng 2006;12:2949-2955.

22 Senyürek I, Klein G, Kalbacher H, Deeg M, Schittek B: Peptides derived from the human laminin a4 and a 5 chains exhibit antimicrobial activity. Peptides 2010;31:1468-1472.

23 Malmsten M, Davoudi M, Schmidtchen A: Bacterial killing by heparin-binding peptides from PRELP and thrombospondin. Matrix Biol 2006;25:294-300.

24 Malmsten M, Davoudi M, Walse B, Rydengård V, Pasupuleti M, Mörgelin M, Schmidtchen A: Antimicrobial peptides derived from growth factors. Growth Factors 2007;25:60-70.

25 Malmström E, Mörgelin M, Malmsten M, Johansson L, Norrby-Teglund A, Shannon O, Schmidtchen A, Meijers JC, Herwald $\mathrm{H}$ : Protein C inhibitor - a novel antimicrobial agent. PLoS Pathog 2009;5:e1000698.

26 Kasetty G, Papareddy P, Kalle M, Rydengård V, Mörgelin M, Albiger B, Malmsten M, Schmidtchen A: The C-terminal sequence of several human serine proteases encodes host defense functions. J Innate Immun 2011;3: 471-482. 